\title{
Inflation of comparator stimuli following CS training
}

\author{
RALPH R. MILLER, STEVE C. HALLAM, and NICHOLAS J. GRAHAME \\ State University of New York, Binghamton, New York
}

\begin{abstract}
Water-deprived rats served in seven conditioned lick suppression experiments designed to assess the effects on responding to a target CS of a series of unsignaled USs given in the training context following completion of CS training. Such treatment has been hypothesized to increase (inflate) the associative strength of the background cues from training (putatively, the CS's comparator stimuli), thereby reducing responding to excitatory CSs and increasing the inhibitory potential of inhibitory CSs. Although posttraining extinction (deflation) of the CS's comparator stimuli usually decreases inhibitory potential and increases excitatory potential of the target CS, posttraining inflation of the comparator stimuli had no effect on either excitatory responding to the target CS or summation test performance indicative of conditioned inhibition. This outcome was consistently obtained across a number of training, inflation, and test conditions selected to maximize sensitivity to any possible effects of comparator inflation. Implications of these null results for the comparator hypothesis of conditioned response generation are discussed.
\end{abstract}

The comparator hypothesis (Miller \& Matzel, 1988; Miller \& Schachtman, 1985) is a response rule that posits that conditioned responding is not only a positive function of the associative strength of the target conditioned stimulus (CS) at the time of testing, but is also a negative function of the associative strength at the time of testing of other stimuli (comparator stimuli) that were present during training (even when CS testing occurs outside the training context). The associative structure underlying the comparator hypothesis is illustrated in Figure 1. Presentation of the CS at the time of testing is presumed to activate both a representation of the unconditioned stimulus (US) that is dependent on the CS-US linkage (Association 1) and a representation of the comparator stimuli that is dependent on the CS-comparator stimuli linkage (Association 2 , which is necessary only when testing occurs in the absence of comparator stimuli). The active representation of the comparator stimuli, in turn, activates a representation of the US that is dependent on the comparator-US linkage (Association 3). Conditioned responding to the CS is hypothesized to reflect a comparison between these two US representations activated on the test trial. (Thus, the comparator hypothesis assumes the tristence of multiple representations of the LS.) Excitatory behavior is

\footnotetext{
Support for this research was provided by NIMH Grant 33881, NSF Grant BSN 86-00755, and the SUNY-Binghamton Center for Cognitive and Psycholinguistic Sciences. Thanks are due Juan Castillo and James Esposito for running several of the experiments, Wesley J. Kasprow, Louis D. Matzel, and Todd R. Schachtman for contributing to the conceptualization of the problem, and $\mathrm{H}$. Moore Arnold, Robert Barnet, and Wesley J. Kasprow for their comments on an earlier version of the manuscript. Requests for reprints should be addressed to Ralph R. Miller, Department of Psychology, SUNY-Binghamton, Binghamton, NY 13901 .
}

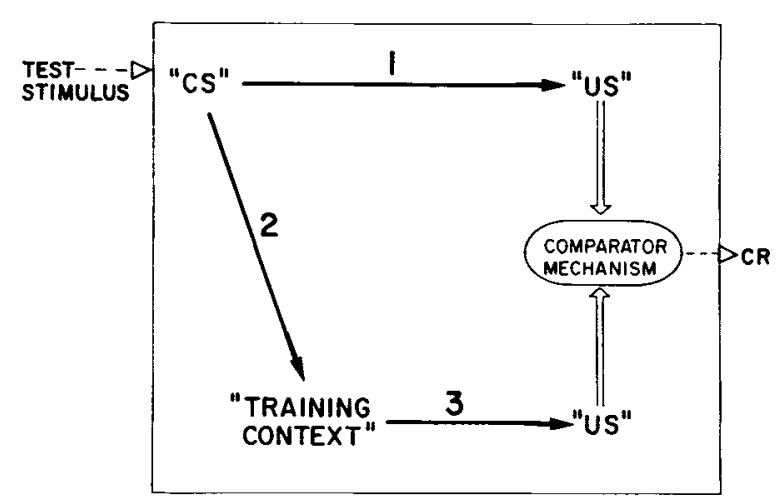

Figure 1. Associative structure assumed by the comparator hypothesis. See text for details.

expected when the US representation based on the CS is large, relative to that based on the comparator stimuli; inhibitory behavior is expected when the US representation based on the CS is small, relative to that based on the comparator stimuli. The comparator stimuli are some combination of the background cues that were present during training and any punctate cues that occurred proximal to the target CS during training. The exact weights of different comparator cues presumably are determined by the relative saliencies of the candidate cues.

The comparator hypothesis makes many behavioral predictions that are identical to those generated by most contemporary theories of acquisition (e.g., Rescorla \& Wagner, 1972). For instance, inflation of what we have termed comparator stimuli is well known to attenuate excitatory responding to a $\mathrm{CS}$ when the inflation occurs before or during CS training (US-preexposure effect and 
negative contingency training, respectively). However, the comparator hypothesis is unique in predicting that alteration of the associative status of the comparator stimuli following CS training will influence subsequent responding to the CS, even when testing occurs outside the presence of any of the comparator cues from training. Specifically, posttraining extinction (associative deflation) of the comparator stimuli should decrease the inhibitory potential and increase the excitatory potential of the CS, and posttraining associative inflation of the comparator stimuli should increase the inhibitory potential and decrease the excitatory potential of the CS. The predictions concerning posttraining extinction of comparator stimuli, in large part, have been supported. Some examples of this, using excitatory stimuli, include overshadowing (Matzel, Schachtman, \& Miller, 1985) and US preexposure (Matzel, Brown, \& Miller, 1987); other examples, using inhibitory stimuli, include negative contingency training (Kasprow, Schachtman, \& Miller, 1987; Schachtman, Brown, Gordon, Catterson, \& Miller, 1987) and Pavlovian inhibition training (Hallam, Matzel, Sloat, \& Miller, 1990).

However, there have been almost no reports concerning posttraining inflation of comparator stimuli. Limited evidence that the comparator hypothesis is wrong with respect to posttraining inflation was reported by Kaplan and Hearst (1985) as part of an experimental series that succeeded in obtaining some of the expected effects of posttraining extinction. Our laboratory has performed numerous experiments attempting to obtain comparator effects of posttraining inflation. All of these efforts found that posttraining inflation of the comparator stimuli, unlike posttraining extinction, has no appreciable effect on the response potentials of the target CS. In this paper, we report a selection of seven of these failures, which collectively lead us to conclude that the comparator hypothesis is wrong with respect to the effects of posttraining inflation. The experiments differ with respect to original training of the CS, details of posttraining inflation treatment, and/or nature of testing. However, in all of the experiments, the subjects were tested in contexts that were equally excitatory for all groups, so as to prevent differential associative summation of the CS with the test context.

\section{EXPERIMENT 1}

In the absence of unsignaled USs, we reinforced a target CS (white noise) on $25 \%$ of its presentations, thereby making the CS a weak excitor. Experimental subjects then were given extensive inflation of the training context in the form of unsignaled USs. The latter procedure was intended to make the training context more excitatory than the target CS. Finally, a summation test for inhibition was administered, in which the CS was compounded with an excitor (clicks). Previous research with the same parameters has found that, when these CS training trials and unsignaled USs are presented in an intermingled fashion, the $\mathrm{CS}$ becomes a conditioned inhibitor capable of passing both retardation and negative summation tests (Schachtman et al., 1987). According to the comparator hypothesis, the present posttraining inflation manipulation should have transformed the initially excitatory CS into a conditioned inhibitor. More traditional models, such as that of Rescorla and Wagner (1972), would predict that the noise would remain excitatory despite inflation of the training context. Thus, there should be associative summation of the clicks and noise, which would be evidenced in more fear of the click-noise compound than fear of the clicks alone. No control for context specificity was included (i.e., there was no group that received posttraining inflation of a context other than Context Train), because we planned to run a context-specificity study later if an inflation effect were found in the present study.

\section{Method}

Subjects. The subjects were 48 naive, adult, male and female, Sprague-Dawley-descended rats bred in our colony from Holtzman stock (Madison, WI). Bodyweight ranges (across all experiments) were 195-470 $\mathrm{g}$ for males and 150-305 $\mathrm{g}$ for females. The subjects were assigned to four treatment groups counterbalanced for sex, litter of origin, body weight, and baseline lick performance prior to differential treatment $(n s=12)$. Prior to the study, all subjects were progressively deprived of water and, by Day 1 , were limited to $10 \mathrm{~min}$ per day of home-cage access to water provided 18-22 h prior to any treatment scheduled for the following day. Purina Laboratory Chow was freely available in the home cages.

Apparatus. Three types of enclosures were used. Enclosure Clear was a clear, rectangular, Plexiglas chamber measuring $22.75 \times 8.25 \times 13 \mathrm{~cm}(1 \times \mathrm{w} \times \mathrm{h})$ and was housed in an environmental chest. The floor was constructed of $0.48-\mathrm{cm}$-diameter stainless steel rods ( $1.5 \mathrm{~cm}$ center to center), connected by NE- 2 neons, which allowed delivery of $0.7-\mathrm{mA}, 0.5-\mathrm{sec}$ footshock. Dim illumination was provided by a $7-\mathrm{W}$ incandescent bulb mounted on a wall of the environmental chest approximately $30 \mathrm{~cm}$ from the animal chamber.

Enclosure Black was a $30-\mathrm{cm}$-long box in a truncated- $V$ shape (28 cm high and $21 \mathrm{~cm}$ wide at the top, narrowing to $5.25 \mathrm{~cm}$ wide at the bottom). The floor and $30-\mathrm{cm}$ sides were sheet metal. It too was housed in an environmental chest. The floor of Enclosure Black consisted of two $30-\mathrm{cm}$-long parallel metal plates, each $2 \mathrm{~cm}$ wide, separated by a $1.25-\mathrm{cm}$ gap. A $0.7-\mathrm{mA}, 0.5-\mathrm{sec}$ footshock could be delivered through the floor. The short walls were black Plexiglas, and the roof was clear Plexiglas. Enclosure Black was dimly illuminated by a $7-\mathrm{W}$ bulb mounted on a wall of the environmental chest approximately $30 \mathrm{~cm}$ from the animal chamber.

Both Enclosures Clear and Black had lick tubes, left-right centered, protruding $1.25 \mathrm{~cm}$ from a narrow wall, $2.5 \mathrm{~cm}$ above the floor. For half of the subjects in each group, target-CS training occurred in Enclosure Clear and target-CS testing occurred in Enclosure Black. For the remaining subjects, these designations were reversed. Hereafter, the training location is called Context Train and the test location is called Context Test.

Context Long measured $50.0 \times 16.7 \times 74.5 \mathrm{~cm}(1 \times \mathrm{w} \times \mathrm{h})$ and had a floor of $0.64-\mathrm{cm}$-diameter stainless steel rods $(1.59 \mathrm{~cm}$ center to center), which were oriented parallel to the $50-\mathrm{cm}$-long walls. The floor grids were connected by NE- $2 \mathrm{H}$ neons and allowed delivery of a 2.0-mA, 2.0-sec footshock. Context Long was brightly lighted and contained no lick tube.

Nominal CSs in Contexts Train and Test were provided by two speakers on opposite walls of their environmental chests. One 
speaker could deliver a white noise or a $3000-\mathrm{Hz}$ tone, both $8 \mathrm{~dB}(\mathrm{C})$ (re. SPL) above a 74-dB(C) ambient sound level. The other speaker could deliver a $3 / \mathrm{sec}$ click train $10 \mathrm{~dB}(\mathrm{C})$ above background. An overhead speaker could provide the $3 / \mathrm{sec}$ click train in Context Long.

Procedure. See Table 1. Adaptation: On Days 1-4, all subjects were exposed to each of the three contexts for 20 min daily, with the order of exposure counterbalanced across subjects. Times to complete the first and second 5 cumulative seconds of drinking (licking) in the first context of each adaptation day were recorded.

Target training: On Days 5, 6, 10, and 11, each subject spent $60 \mathrm{~min}$ in Context Train. Randomly distributed within these sessions were eight 60 -sec CS presentations, two of which were reinforced at offset with $0.5-\mathrm{sec}, 0.7-\mathrm{mA}$ footshock. For Groups $\mathrm{N}+\mathrm{C}$, $\mathrm{N}+\mathrm{CN}$, and $\mathrm{N}-\mathrm{N}$, this $\mathrm{CS}$ was the white noise (N). For Group $\mathrm{T}-\mathrm{N}$, the $\mathrm{CS}$ was the tone (T).

Nontarget training: On Days 7-9, all subjects were placed in Context Long for $1 \mathrm{~h}$ per day. On Day 7, no nominal stimulus was delivered. On Day 8 and again on Day 9 , every animal received four 60-sec click exposures, each of which terminated with a 2-sec, $2-\mathrm{mA}$ footshock. Preliminary studies showed that this relatively high shock intensity was necessary to obtain appreciable suppression to the clicks in Context Test, presumably owing to stimulus generaliza- tion decrement arising from the context switch between click training and testing.

Inflation treatment: On Days 12-15, all subjects were placed in Context Train for $1 \mathrm{~h}$ daily. During each of these sessions, the subjects in Groups $\mathrm{N}+\mathrm{C}$ and $\mathrm{N}+\mathrm{CN}$ received 42 unsignaled, $0.5-\mathrm{sec}$, $0.7-\mathrm{mA}$ footshocks $(+)$, whereas Groups $\mathrm{N}-\mathrm{N}$ and $\mathrm{T}-\mathrm{N}$ received no treatment $(-)$. Lick latencies were recorded.

Baseline recovery: On Day 16, all subjects were placed in Context Test for $1 \mathrm{~h}$. Lick latencies were recorded.

Testing: On Day 17, all subjects were placed in Context Test for $11 \mathrm{~min}$. Upon completion of 5 cumulative seconds of licking, the test stimuli were presented and stayed on until 5 additional seconds of licking were completed. For Group $\mathrm{N}+\mathrm{C}$, the test $\mathrm{CS}$ was the clicks (C); for Group $N+C N$, it was a compound of the clicks and white noise (CN). For Groups N-N and T-N, it was the white noise $(\mathrm{N})$ alone. All latencies were converted to log (base 10) latencies to permit the use of parametric statistics.

\section{Results and Discussion}

One subject in Group T-N was eliminated from the study due to illness. In neither this nor any of the follow-

Table 1

Critical Aspects of Experimental Procedures

\begin{tabular}{|c|c|c|c|c|c|}
\hline Experiment & Group & $\begin{array}{c}\text { Target } \\
\text { Training } \\
\text { in Context } \\
\text { Train } \\
\end{array}$ & $\begin{array}{c}\text { Nontarget } \\
\text { Training } \\
\text { in Context } \\
\text { Long } \\
\end{array}$ & $\begin{array}{c}\text { Posttraining } \\
\text { Treatment } \\
\text { in Context } \\
\text { Train } \\
\end{array}$ & $\begin{array}{c}\text { Target } \\
\text { Test } \\
\text { in Context } \\
\text { Test }\end{array}$ \\
\hline 1 & $\begin{array}{l}\mathrm{N}+\mathrm{C} \\
\mathrm{N}+\mathrm{CN} \\
\mathrm{N}-\mathrm{N} \\
\mathrm{T}-\mathrm{N}\end{array}$ & $\begin{array}{l}24 \mathrm{~N}-/ 8 \mathrm{~N}+ \\
24 \mathrm{~N}-/ 8 \mathrm{~N}+ \\
24 \mathrm{~N}-/ 8 \mathrm{~N}+ \\
24 \mathrm{~T}-/ 8 \mathrm{~T}+\end{array}$ & $\begin{array}{l}8 \mathrm{C}+ \\
8 \mathrm{C}+ \\
8 \mathrm{C}+ \\
8 \mathrm{C}+\end{array}$ & $\begin{array}{c}168+ \\
168+ \\
- \\
-\end{array}$ & $\begin{array}{l}\mathrm{C} \\
\mathrm{CN} \\
\mathrm{N} \\
\mathrm{N}\end{array}$ \\
\hline 2 & $\begin{array}{l}\mathrm{N}+ \\
\mathrm{N}- \\
\mathrm{T}-\end{array}$ & $\begin{array}{l}24 \mathrm{~N}-/ 8 \mathrm{~N}+ \\
24 \mathrm{~N}-/ 8 \mathrm{~N}+ \\
24 \mathrm{~T}-/ 8 \mathrm{~T}+\end{array}$ & & $\begin{array}{c}168+ \\
- \\
-\end{array}$ & $\begin{array}{l}\mathbf{N} \\
\mathbf{N} \\
\mathbf{N}\end{array}$ \\
\hline 3 & $\begin{array}{l}\text { N-Tr-C } \\
\text { N-Tr-CN } \\
\text { N-Ir-C } \\
\text { N-Ir-CN } \\
\text { T-Tr-C } \\
\text { T-Tr-CN } \\
\text { T-Ir-C } \\
\text { T-Ir-CN }\end{array}$ & $\begin{array}{l}120 \mathrm{~N}- \\
120 \mathrm{~N}- \\
120 \mathrm{~N}- \\
120 \mathrm{~N}- \\
120 \mathrm{~T}- \\
120 \mathrm{~T}- \\
120 \mathrm{~T}- \\
120 \mathrm{~T}-\end{array}$ & $\begin{array}{l}8 \mathrm{C}+ \\
8 \mathrm{C}+ \\
8 \mathrm{C}+ \\
8 \mathrm{C}+ \\
8 \mathrm{C}+ \\
8 \mathrm{C}+ \\
8 \mathrm{C}+ \\
8 \mathrm{C}+\end{array}$ & $\begin{array}{c}48+ \\
48+ \\
- \\
- \\
48+ \\
48+ \\
- \\
-\end{array}$ & $\begin{array}{c}\mathrm{C} \\
\mathrm{CN} \\
\mathrm{C} \\
\mathrm{CN} \\
\mathrm{C} \\
\mathrm{CN} \\
\mathrm{C} \\
\mathrm{CN}\end{array}$ \\
\hline 4 & $\begin{array}{l}\text { Tr* } \\
\mathrm{Ir}^{*}\end{array}$ & $\begin{array}{l}24 \mathrm{~N}+ \\
24 \mathrm{~N}+\end{array}$ & & $\begin{array}{c}168+ \\
-\end{array}$ & $\begin{array}{l}\mathbf{N} \\
\mathbf{N}\end{array}$ \\
\hline 5 & $\begin{array}{l}\text { 4-1Tr } \\
4-1 \mathrm{Lo} \\
4-4 \mathrm{Tr} \\
4-4 \mathrm{Lo} \\
16-1 \mathrm{Tr} \\
16-1 \mathrm{Lo} \\
16-4 \mathrm{Tr} \\
16-4 \mathrm{Lo}\end{array}$ & $\begin{array}{l}60 C+ \\
60 C+ \\
60 C+ \\
60 C+ \\
240 C+ \\
240 C+ \\
240 C+ \\
240 C+\end{array}$ & & $\begin{array}{c}12+ \\
- \\
48+ \\
- \\
12+ \\
- \\
- \\
-\end{array}$ & $\begin{array}{l}C \\
C \\
C \\
C \\
C \\
C \\
C \\
C\end{array}$ \\
\hline 6 & $\begin{array}{l}\text { N-Tr-C } \\
\text { N-Tr-CN } \\
\text { N-Ir-CN } \\
\text { L-Ir-CN }\end{array}$ & $\begin{array}{l}24 \mathrm{~N}-/ 8 \mathrm{~N}+/ 168+ \\
24 \mathrm{~N}-/ 8 \mathrm{~N}+/ 168+ \\
24 \mathrm{~N}-/ 8 \mathrm{~N}+/ 168+ \\
24 \mathrm{~L}-/ 8 \mathrm{~L}+/ 168+\end{array}$ & $\begin{array}{l}8 \mathrm{C}+ \\
8 \mathrm{C}+ \\
8 \mathrm{C}+ \\
8 \mathrm{C}+\end{array}$ & $\begin{array}{c}176+ \\
176+ \\
- \\
-\end{array}$ & $\begin{array}{l}\mathrm{C} \\
\mathrm{CN} \\
\mathrm{CN} \\
\mathrm{CN}\end{array}$ \\
\hline 7 & $\begin{array}{l}\text { LN-N } \\
\text { LN }\end{array}$ & $\begin{array}{l}8 \mathrm{LN}+ \\
8 \mathrm{LN}+\end{array}$ & & $\begin{array}{c}16 \mathrm{~N}+ \\
-\end{array}$ & $\begin{array}{l}\mathrm{L} \\
\mathrm{L}\end{array}$ \\
\hline
\end{tabular}

Note $-\mathrm{C}=$ click train, $\mathrm{N}=$ white noise, $\mathrm{T}=$ tone, $+=$ footshock, $-=$ nonreinforcement, $\mathrm{Tr}=$ Context Train, $\mathrm{L}_{\mathrm{r}}=$ Context Long, $\mathrm{Ir}=$ Context Irrelevant. Numbers represent total presentations across days. Contexts Train, Test, Long, and Irrelevant were distinctly different. See text for details. *Prior to CS training, Context Train was inflated and extinguished. 
ing studies was any difference found between groups on the adaptation days, the first day of target training, the first day of inflation treatment, the baseline recovery day, or the first 5 cumulative seconds of licking on the test day $(p s>.05)$. On the last day of inflation treatment, Groups $\mathrm{N}+\mathrm{C}$ and $\mathrm{N}+\mathrm{CN}$, which received inflation treatment in Context Train, had mean latencies to complete the first 5 cumulative seconds of licking of 2.67 and $2.83 \log \mathrm{sec}$, respectively, whereas Groups N-N and T-N, which did not receive inflation treatment, had mean latencies to complete the first 5 cumulative seconds of licking of 0.93 and $0.89 \log \mathrm{sec}$, respectively. Each of the former two groups differed from the latter two groups (all $p s<.01$ ), indicating that the inflation treatment was highly effective at increasing fear of the training context. This measure of context fear is in some sense confounded because the two inflation groups, $\mathrm{N}+\mathrm{N}$ and $\mathrm{N}+\mathrm{CN}$, received unsignaled footshock $1.78 \mathrm{log} \mathrm{sec},(60 \mathrm{sec})$ into the last inflation session as part of inflation training. But even if individual suppression scores were truncated at $1.78 \mathrm{log} \mathrm{sec}$, the two inflation groups displayed more suppression than did the two noninflation groups (all $p$ s $<.01$ ).

Latencies to complete the second 5 cumulative seconds of licking on the test day (i.e., while the test CSs were present) are depicted in Figure 2. An analysis of variance (ANOVA) found differences between groups $[F(3,43)=$ $11.82, p<.01]$. Planned comparisons found that Group N-N, which was trained with the noise, suppressed licking more than did Group T-N, which was not trained with the noise $[F(1,43)=4.37, p<.05]$. Consequently, we may conclude that the noise was an effective excitor for all subjects that received initial training with the noise. However, in the presence of the noise alone, lick suppression was only modest, presumably owing to the $25 \%$ partial reinforcement schedule used in target training. This relatively low level of suppression indicates that our sensitivity to the consequences of posttraining inflation was not impaired by ceiling effects owing to high fear of the

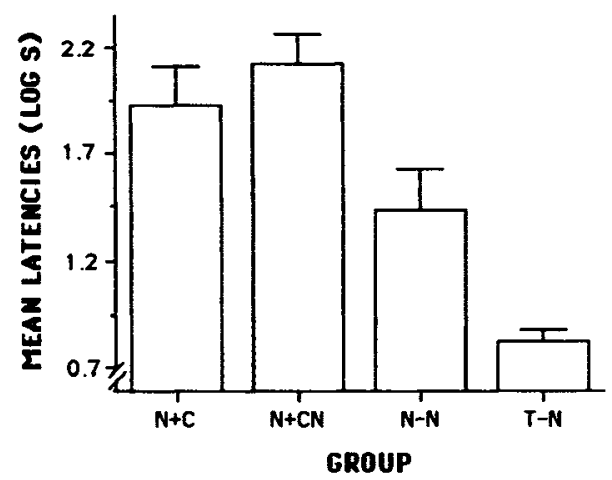

Figure 2. Mean times in Experiment 1 to complete 5 cumulative seconds of licking in the presence of the test CSs, which was the click train for Group $\mathbf{N}+\mathrm{C}$, the white noise for Groups $\mathrm{N}-\mathrm{N}$ and $T-N$, and the click-noise compound for Group $N+C N$. See text for group treatments. Brackets denote standard errors. noise. (A ceiling score was $2.78 \log \mathrm{sec}$.) The clicks alone produced substantial, but less than ceiling, suppression in Group $\mathrm{N}+\mathrm{C}$, which suggests that there was room for the noise to diminish suppression to the clicks in Group $\mathrm{N}+\mathrm{CN}$. However, Group $\mathrm{N}+\mathrm{CN}$ did not differ from Group $\mathrm{N}+\mathrm{C}(F<1.00)$. Thus, there was no hint that posttraining inflation of the CS's comparator stimuli caused the weakly excitatory CS to become a conditioned inhibitor, despite there being reason to think that Experiment 1 would be sensitive to such an effect.

\section{EXPERIMENT 2}

Experiment 1 failed to obtain an effect of posttraining inflation of the training context. Perhaps we were overly ambitious in attempting to convert an overt excitor into a functional inhibitor, and a simple test for excitation might have detected a decrease in excitatory potential of the CS. Experiment 2 was a replication of Experiment 1, except that we used an excitatory test with the target CS. Adaptation to Context Long and click training were omitted, as was Group $\mathrm{N}+\mathrm{C}$, because there was no need for the clicks in the absence of a summation test.

\section{Method}

Subjects. The subjects were 24 rats of the same description as in Experiment 1. The subjects were assigned to three treatment groups $(n s=8)$.

Apparatus. Enclosures Clear and Black from Experiment 1 were used.

Procedure. See Table 1. Adaptation was the same as that on Days 1-4 in Experiment 1. Target training on Days 5-8 was the same as that on Days 5-6 and 10-11 in Experiment 1. Inflation treatment on Days 9-12 for Group N+ consisted of 42 unsignaled, 0.7-mA, 0.5-sec footshocks (+) per day. Groups N-and T- received only equivalent context exposure (-). Baseline recovery treatment on Day 13 was identical to that of Day 16 in Experiment 1 . Testing on Day 14 occurred in Context Test. Upon completion of 5 cumulative seconds of licking, the noise was presented and stayed on until 5 additional seconds of licking were completed.

\section{Results and Discussion}

On the last day of inflation treatment, Group $\mathrm{N}+$, which had received inflation treatment, had a mean latency to complete the first 5 cumulative seconds of licking of $2.71 \log \mathrm{sec}$, whereas Groups $\mathrm{N}$ - and $\mathrm{T}$-, which did not receive inflation treatment, had latencies of 1.01 and $0.88 \log \mathrm{sec}$, respectively. Even when scores were truncated at the time of the first inflation shock on that day $(1.78 \log \mathrm{sec})$, Group $\mathrm{N}+$ differed from the latter two groups (both $p s<.01$ ).

Latencies to complete the second 5 cumulative seconds of licking on the test day (i.e., while the white noise was present) are depicted in Figure 3. An ANOVA found differences between groups $[F(2,21)=3.77, p<.05]$. Planned comparisons determined that Group $\mathrm{N}$-, which had been trained with the noise, suppressed licking more than did Group T-, which had not been trained with the noise $[F(1,21)=3.92, p<.05]$. Consequently, we may conclude that the noise was excitatory for both groups that 


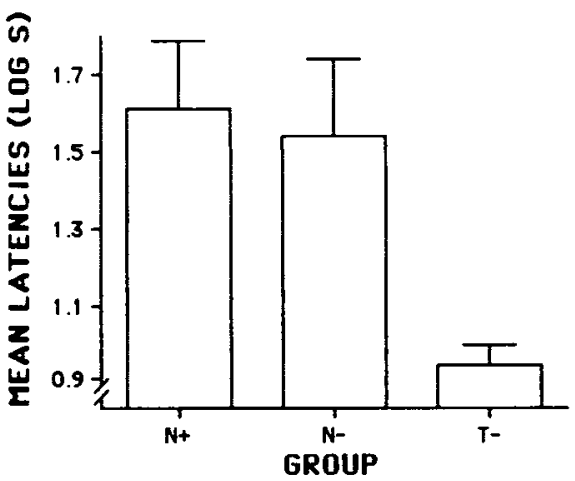

Figure 3. Mean times in Experiment 2 to complete 5 cumulative seconds of licking in the presence of the white noise. See text for group treatments. Brackets denote standard errors.

received initial noise training (i.e., Groups $\mathrm{N}$ - and $\mathrm{N}+$ ). Moreover, the suppression to the white noise displayed by Group $\mathrm{N}$ - was great enough to be sensitive to decreases in fear resulting from inflation of the CS's comparator stimuli and not so high as to lose sensitivity owing to a behavioral ceiling effect. However, the critical planned comparison between Groups $\mathrm{N}+$ and $\mathrm{N}$ - indicated no effect of posttraining inflation of the CS's comparator stimuli $(F<1.00)$. In summary, there was no evidence that posttraining inflation of the CS's comparator stimuli caused a decrease in the excitatory potential of the CS, despite evidence that Experiment 2 should have been sensitive to such an effect.

\section{EXPERIMENT 3}

In our prior successful studies of the effects of posttrial deflation of comparator stimuli, we have generally found it easier to alter a stimulus's inhibitory potential than its excitatory potential (e.g., Hallam et al., 1990). Perhaps Experiment 1 failed to detect an effect of posttraining inflation of the CS's comparator stimuli because the CS was a weak excitor at the onset of inflation training. To assess this possibility, in Experiment 3, original training prior to inflation of the context consisted of repeated nonreinforced exposures to the CS (i.e., a latent inhibition treatment), which is reputed to make the target neither an excitor nor an inhibitor (Reiss \& Wagner, 1972; Rescorla, 1971). Nevertheless, if pretraining exposure to the CS decreases attention to the stimulus, we might not expect high sensitivity to the kinds of effects predicted by the comparator hypothesis to arise from posttraining inflation of the stimulus's comparator stimuli.

Experiment 3 was similar to Experiment 1, except that the target stimulus was never reinforced in original training. The question was whether inflation of the comparator stimulus following CS-preexposure training would convert the stimulus into a functional conditioned inhibitor, as indicated on a summation test. Original training and subsequent inflation treatment collectively amounted to negative contingency, conditioned inhibition training with the CS and US explicitly unpaired; however, in this study, all of the CS presentations occurred prior to any of the US presentations. Experiment 3 further differed from Experiment 1 in that, instead of putting the noninflation (control) subjects in the training context and not giving them unsignaled footshock, we placed these control subjects into an irrelevant context and gave them unsignaled shocks comparable to those experienced by the inflation animals. The last difference from Experiment 1 was that the inflation treatment started $6 \mathrm{~min}$ after the end of the initial treatment, to test the possibility that comparator events are events that occur proximal to the target training events not only in space, but in time as well. The study used a $2 \times 2 \times 2$ factorial design with the following factors: CSpreexposure treatment with the target cue (white noise) or irrelevant cue (tone), inflation of the initial treatment context or an irrelevant context, and testing with the excitor alone (clicks) or a compound stimulus composed of the clicks and noise.

\section{Method}

Subjects. The subjects were 48 rats of the same description as in Experiment 1. The subjects were assigned to eight treatment groups $(n s=6)$.

Apparatus. Contexts Train, Test, and Long from Experiment 1 were used. Additionally, a fourth context (Context Irrelevant) served as the location for unsignaled footshock as a control treatment for the animals that were not given unsignaled footshock (i.e., associative inflation) in the training context. Context Irrelevant was a rectangular box $24.1 \times 12.7 \times 20 \mathrm{~cm}(1 \times w \times h)$ housed in an environmental chest. Three of the walls were made of white Plexiglas; the ceiling and remaining sidewall were made of clear Plexiglas. There was no illumination in this context. Chamber floors consisted of stainless steel rods, $0.5 \mathrm{~cm}$ in diameter and $1.3 \mathrm{~cm}$ center to center, interconnected with NE-2 neon bulbs.

Procedure. See Table 1. Adaptation on Day 1 consisted of $26 \mathrm{~min}$ of exposure to Context Train. On Day 2, each animal received $26 \mathrm{~min}$ of exposure to Context Test. CS target training on Days $3,4,8$, and 9 consisted of each subject spending $1 \mathrm{~h}$ in Context Train. Groups N-Tr-C, N-Tr-CN, N-Ir-C, and N-Ir-CN received 30 daily 15 -sec exposures to the white noise $(\mathrm{N})$ randomly distributed within the 1-h session. Groups T-Tr-C, T-Tr-CN, T-Ir-C, and $T-I r-C N$ received identical treatment, except that a $2000-\mathrm{Hz}$ tone (T) 8-dB(C) above background was substituted for the white noise. Excitor training for the summation test occurred on Days 5-7 exactly as that on Days 7-9 in Experiment 1. Inflation treatment began immediately after the end of target treatment (nonreinforced exposure to the CS) on Day 9. Groups N-Tr-C, N-Tr-CN, T-Tr-C, and T-Tr-CN were left in Context Train, whereas Groups N-Ir-C, $\mathrm{N}-\mathrm{Ir}-\mathrm{CN}, \mathrm{T}-\mathrm{Ir}-\mathrm{C}$, and $\mathrm{T}-\mathrm{Ir}-\mathrm{CN}$ were placed in Context Irrelevant. Six minutes later, a 26 -min session began that included 12 randomly distributed, unsignaled footshocks (USs) of $0.7 \mathrm{~mA}$ for $2 \mathrm{sec}$. The 26-min inflation session in Context Train or Context Irrelevant of Day 9 was repeated on Days 10,11 , and 12. Baseline recovery on Day 13 was the same as that on Day 16 in Experiment 1 . Testing on Day 14 was identical to that on Day 17 in Experiment 1, with Groups $\mathrm{N}-\mathrm{Tr}-\mathrm{C}, \mathrm{T}-\mathrm{Tr}-\mathrm{C}, \mathrm{N}-\mathrm{Ir}-\mathrm{C}$, and $\mathrm{T}-\mathrm{Ir}-\mathrm{C}$ receiving the clicks and Groups N-Tr-CN, T-Tr-CN, N-Ir-CN, and T-Ir-CN receiving the click-noise compound. All subjects were returned to Context Train on Day 15 for $15 \mathrm{~min}$, and latencies to complete the first 5 cumulative seconds of licking were recorded.

\section{Results and Discussion}

On Day 15, an ANOVA detected more fear of Context Train in animals that received inflation treatment in Con- 


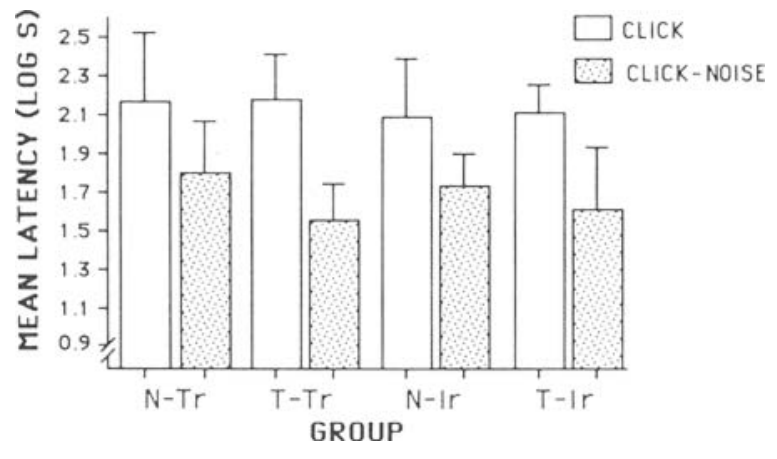

Figure 4. Mean times in Experiment 3 to complete 5 cumulative seconds of licking in the presence of the test CSs, which was the click train for groups with designations ending with $C$ and the click -noise compound for groups with designations ending with $\mathrm{CN}$. See text for group treatments. Brackets denote standard errors.

text Train $(2.04 \log \mathrm{sec})$ than in those that received inflation in Context Irrelevant $(1.25 \log \sec )[F(1,40)=31.14$, $p<.001]$. Thus, the contextual inflation was successful.

Day 14 mean times to complete 5 cumulative seconds of licking in the presence of the test stimuli in Context Test are depicted in Figure 4. An ANOVA found an effect of test $\operatorname{CS}[F(1,40)=6.31, p<.05]$, indicating that the clicks alone produced more fear than did the clicks compounded with the noise. This observation is consistent with either the noise serving as an external inhibitor of fear or a source of generalization decrement. (That the noise had not become a conditioned inhibitor is indicated by the performance of the tone groups, see below.) However, the important finding is that there was no difference between groups tested with the compound as a function of whether or not Context Train was inflated after initial treatment with the white noise $(p>.25)$. Thus, there was no effect on responding to the CS as a function of inflating the comparator stimuli after initial CS training.

Incidentally, Experiment 3 obtained similar effects of the noise on suppression to the clicks in groups that were trained with the tone and groups that were trained with the white noise. That is, the noise was not a conditioned inhibitor because it had the same effect whether it was novel or preexposed. This indicates that CS preexposure to the noise did not contribute to the observed negative summation effect. Consequently, the present data are consistent with the prior findings of Reiss and Wagner (1972) and Rescorla (1971) that CS preexposure does not make the stimulus into a conditioned inhibitor that is able to pass both a summation test and a retardation test.

\section{EXPERIMENT 4}

The preceding failures to obtain the effects of posttraining inflation of comparator stimuli that are predicted by the comparator hypothesis contrast sharply with our frequent successes in obtaining the predicted effects of posttraining extinction of comparator stimuli (e.g., Hallam et al., 1990; Kasprow et al., 1987; Matzel et al., 1985, 1987; Schachtman et al., 1987). This discrepancy arises either from a fundamental asymmetry in the consequences of posttraining modification of the comparator stimuli or from some confounding difference between the procedures used to assess the effects of inflating comparator stimuli and those used to assess the effects of extinguishing comparator stimuli. One distinct discrepancy between the procedures used to demonstrate the consequences of posttraining extinction and posttraining inflation that might explain the asymmetry of these effects without concluding that a fundamental asymmetry exists is the difference in associative history of the comparator stimuli at the time of training. In our demonstrations of the effects of posttraining extinction (particularly those in which the training context serves as the comparator stimulus), posttraining extinction of the comparator stimuli consists of returning the contextual cues to the relatively neutral associative state they were in during initial adaptation. In contrast, inflation typically consists of moving the contextual cues to a new associative state that they had not previously occupied. It is possible that posttraining modification of comparator stimuli is effective only when the comparator stimuli are being returned to an associative state that they previously occupied. Experiment 4 tested this alternative. Specifically, we examined posttraining inflation of a CS's comparator stimuli (the training context in this case) with subjects for which the training context had first been made excitatory and then extinguished prior to CS training. If restoration to a prior associative state is necessary to obtain effects of posttraining modification of the comparator stimuli, under these conditions, an effect of posttraining inflation should be seen. An excitation test was used.

\section{Method}

Subjects. The subjects were 24 rats of the same description as in Experiment 1. The subjects were assigned to two treatment groups $(n \mathrm{~s}=12)$.

Apparatus. Contexts Train, Test, and Irrelevant were used.

Procedure. See Table 1. Adaptation to the apparatus consisted of all subjects spending $1 \mathrm{~h}$ in Context Test on Day 1 . Initial inflation of Context Train occurred on Days 2-5. Each subject spent $1 \mathrm{~h}$ per day in Context Train, during which it received daily 42 randomly distributed, unsignaled, 0.7-mA, 0.5-sec footshocks. Pretraining extinction of Context Train occurred on Days 6-11. Each subject spent $1.5 \mathrm{~h}$ daily in Context Train, during which no nominal CSs or USs were delivered. Target-CS training occurred on Days 12-15. Each subject spent $1 \mathrm{~h}$ per day in Context Train, during which there were six randomly distributed 60 -sec white noise (CS) presentations, each of which terminated with onset of a $0.7-\mathrm{mA}$, 0.5 -sec footshock. Inflation treatment occurred on Days 16-19. The subjects in Group Tr were placed in Context Train for $1 \mathrm{~h}$ daily, during which they received $420.7-\mathrm{mA}, 0.5$-sec unsignaled foot shocks. The subjects in Group Ir received equivalent shock in Context Irrelevant. On Day 20, all subjects were placed in Context Test for $1 \mathrm{~h}$ to allow recovery of baseline licking. Testing occurred on Day 21. All subjects were placed in Context Test for $11 \mathrm{~min}$. Upon completion of the first 5 cumulative seconds of licking, the white noise was presented and stayed on until 5 additional seconds of lick- 
ing were completed. On Day 22, all subjects were placed in Context Train, and times to complete the first 5 cumulative seconds of licking were recorded.

\section{Results and Discussion}

On the last day of initial inflation (Day 5), the overall mean time to complete the first 5 cumulative seconds of licking was $2.47 \log \mathrm{sec}$; on the last day of pretraining deflation (Day 11), the overall mean time to complete the first 5 cumulative seconds of licking was $1.21 \mathrm{log} \mathrm{sec}$. A within-subjects comparison found that these two means differed $[F(1,22)=8.87, p<.01]$. This statistic demonstrates that initial inflation and pretraining deflation treatments produced their intended effects of first making the context excitatory and then, through extinction, eliminating that excitation. On Day 22, the mean time to complete the first 5 cumulative seconds of licking in Context Train was $2.29 \mathrm{log} \sec$ for Group Tr, whereas it was $1.35 \mathrm{log}$ sec for Group Ir $[F(1,22)=6.37, p<.05]$. This difference in suppression indicates that the posttraining inflation of Context Train experienced by Group $\operatorname{Tr}$ was both effective and context specific.

On the CS test day (Day 21), Group Tr had a mean of $1.37 \mathrm{log}$ sec to complete its second 5 cumulative seconds of licking (i.e., in the presence of the white noise), whereas Group Ir had a mean of $1.26 \log \sec [F(1,22)<1.00]$. Thus, posttraining inflation of the training context did not decrease conditioned responding (in this case, lick suppression) to the CS, even when the subjects had pretraining experience with the training context being excitatory.

\section{EXPERIMENT 5}

In each of the preceding failures to obtain an inflation effect, demonstrable context-US associations were not evident prior to context inflation. Possibly, subjects do not pay sufficient attention to a neutral context to allow the formation of a strong CS-context association. If this were so, the weak CS-context association might be inadequate to support strong comparator effects (see Association 2 in Figure 1). The rationale for the training contexts in the prior studies to be neutral at the time of CS training was to provide room for a large associative difference between the training context with and without subsequent inflation. To determine if inadequate attention to the context during CS training was the reason for the absence of comparator effects in the prior experiments, the training context in Experiment 5 was made slightly excitatory during CS training for all subjects. Then, following CS training, it was made highly excitatory (inflation) for some subjects. Furthermore, in Experiment 5, two degrees of CS training were employed (4 and 16 days), because we thought that more days of CS training might strengthen the CS-context association that is presumably necessary for strong comparator effects (see Figure 1). Additionally, two degrees of inflation (1 and 4 days) were used, because we thought it possible that excessive exposure to the training context during the in- flation treatment might have extinguished the CS-context association in the previous experiments. Finally, a test for CS excitation was administered. In summary, Experiment 5 used a $2 \times 2 \times 2$ factorial design, with 4 or 16 days of CS training, 1 or 4 days of inflation treatment, and inflation treatment being inside or outside the training context (Context Train vs. Context Long).

\section{Method}

Subjects. The subjects were 48 rats of the same description as in Experiment 1. The subjects were assigned to eight treatment groups $(n s=6)$.

Apparatus. Contexts Train, Test, and Long from Experiment 1 were used.

Procedure. See Table 1. Adaptation treatment consisted of exposing all subjects for $1 \mathrm{~h}$ to Context Train on Day 1 , Context Test on Day 2, and Context Long on Day 3. For target-CS training, Groups 4-1Tr, 4-1Lo, 4-4Tr, and 4-4Lo spent $1 \mathrm{~h}$ daily in Context Train on Days 4-7. During each session, there were eight 15-sec click train $(6 / \mathrm{sec})$ presentations, four of which were immediately followed by a $0.7-\mathrm{mA}, 0.5$-sec footshock. Additionally, during every other session starting with the first, intermingled among the training trials was one unsignaled, 0.7-mA, 0.5-sec shock. Recent unpublished research in our laboratory has indicated that even very low densities of unsignaled shock can produce measurable fear of the context and that slightly higher densities of unsignaled shock produce a profound attenuation in responding to the CS (Hallam \& Miller, 1988). For Groups 16-1 Tr, 16-1Lo, 16-4Tr, and 16-4Lo, the same treatment prevailed on Days 4-19. Inflation treatment began on the day after completion of CS training. The subjects in Groups 4-1Tr and 16-1Tr were placed in Context Train for $26 \mathrm{~min}$, during which they received $120.5-\mathrm{sec}, 0.7-\mathrm{mA}$ unsignaled shocks. For Groups 4-4Tr and 16-4Tr, the same treatment prevailed for 4 days. Except for the inflation treatment occurring in Context Long, Groups 4-1Lo and 16-1Lo were treated in the same way as were Groups 4-1Tr and 16-1 Tr; Groups 4-4Lo and 16-4Lo were treated in the same way as were Groups 4-4Tr and 16-4Tr. Baseline recovery and excitatory testing with the $\mathrm{CS}$ and then testing with Context Train occurred over three consecutive days, as in Experiment 4.

\section{Results and Discussion}

On the second test, which assessed lick suppression in the training context, there was a main effect of inflation: Inflation of Context Train yielded more suppression (1.80 log sec) than did inflation of Context Long (1.39 log $\sec )[F(1,40)=7.10, p<.01]$. Moreover, 4 days of inflation in Context Train produced more suppression $(2.01 \log \mathrm{sec})$ than did 1 day of inflation in Context Train $(1.60 \log \sec )[F(1,40)=7.15, p<.01]$. Collectively, these results indicate that the associative inflation treatment effectively increased context fear.

Latencies to complete the 5 cumulative seconds of licking in the presence of the CS on the first test day are depicted in Figure 5. The only effect that an ANOVA found significant was the interaction between place of inflation (Context Train vs. Context Long) and the duration of inflation ( 1 vs. 4 days) $[F(1,40)=5.08, p<.05]$. This interaction was found to arise from less fear in the control subjects that received 1 day of inflation treatment in Context Long $(p<.05)$, and it is therefore not supportive of the comparator hypothesis, which would predict such a difference only following inflation treatment in 


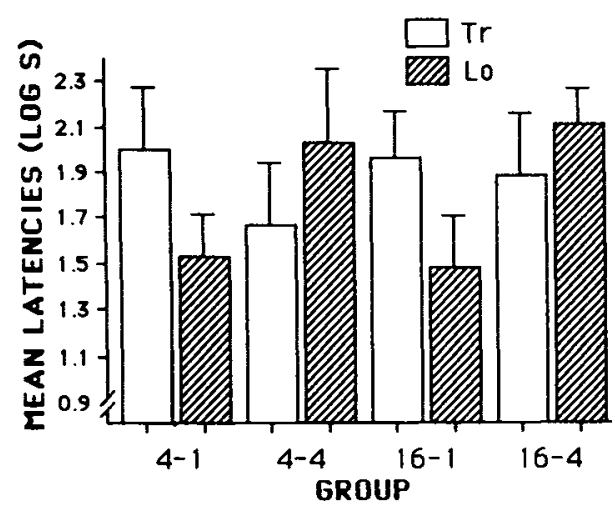

Figure 5. Mean times in Experiment 5 to complete 5 cumulative seconds of licking in the presence of the click train. See text for group treatments. Brackets denote standard errors.

Context Train. Thus, the present observations failed to detect an effect of posttraining inflation of the training context, despite efforts to increase attention to the context during CS training.

\section{EXPERIMENT 6}

Some of the strongest effects of posttraining extinction of comparator stimuli have taken the form of decreased conditioned inhibition (e.g., Hallam et al., 1990; Kaplan \& Hearst, 1985; Kasprow et al., 1987; Schachtman et al., 1987). Experiments 1 and 3 used summation tests for inhibition; however, in Experiment 1, posttraining inflation began with the target CS being excitatory, whereas, in Experiment 3, inflation began with the target stimulus having already been presented in the absence of any reinforcement (i.e., CS preexposure). Consequently, in Experiment 6 , we used the same negative contingency training parameters that Schachtman et al. (1987) used to produce a weak conditioned inhibitor on summation and retardation tests, and we then inflated the training context following inhibitory training to see if such treatment increased conditioned inhibition. A summation test was used to assess inhibitory potential. To use fewer animals, only one control group was tested on the excitor alone, with our intent being to rerun the study with additional control groups if an inflation effect was observed.

\section{Method}

Subjects. The subjects were 48 rats of the same description as in Experiment 1. The subjects were assigned to four treatment groups $(n s=12)$.

Apparatus. Contexts Train, Test, Long, and Irrelevant from Experiments 1 and 3 were used.

Procedure. See Table 1. On Days 1-4, all subjects were adapted to Contexts Train, Test, and Long as in Experiment 1. For target treatment on Days 5, 6, 10, and 11 , each subject spent $1 \mathrm{~h}$ in Context Train, during which there were eight 60 -sec CS presentations, two of which were reinforced with a $0.5-\mathrm{sec}, 0.7-\mathrm{mA}$ footshock. For Groups N-Tr-C, N-Tr-CN, and N-Ir-CN, the CS was the white noise (N). For Group L-Ir-CN, the CS was a flashing $(0.5 \mathrm{sec}$ on $/ 0.5 \mathrm{sec}$ off) 75 -W light (L) approximately $40 \mathrm{~cm}$ from the subject. Additionally, during each training session 42 unsignaled, $0.5-\mathrm{sec}, 0.7-\mathrm{mA}$ shocks were administered. Nontarget training in Context Long on Days 5-7 was identical to that in Experiment 1. Inflation treatment occurred on Days 12-19; subjects in Groups $\mathrm{N}-\mathrm{Tr}-\mathrm{CN}$ and $\mathrm{N}-\mathrm{Tr}-\mathrm{C}$ were placed in Context Train for $30 \mathrm{~min}$, whereas subjects in Groups L-Ir-CN and N-Ir-CN were placed in Context Irrelevant for $30 \mathrm{~min}$. During each session, 22 unsignaled, 0.5 -sec, 1.8-mA footshocks were given. This shock density was the same as that during inhibition training, but the intensity of shock was raised from $0.7 \mathrm{~mA}$, with our intent being to increase fear of the training context relative to that produced during inhibition training. Baseline recovery in Context Test on Day 20, CS testing on Day 21, and Context Train testing on Day 22 were the same as in Experiment 4. On Day 21, Group N-Tr-C was tested with the clicks, whereas Groups N-Tr-CN, N-Ir-CN, and L-Ir-CN were tested with a compound of the clicks and noise.

\section{Results and Discussion}

On Day 22, the two groups that received inflation treatment in Context Train (Groups N-Tr-C and N-Tr-CN) had a mean latency of $2.43 \mathrm{log} \sec$ to complete their first 5 cumulative seconds of licking, in contrast to the subjects that received analogous treatment in Context Irrelevant (Groups N-Ir-CN and L-Ir-CN), for which the mean was $1.80 \log \sec [F(1,44)=4.49, p<.05]$. Thus, the context was successfully inflated.

Mean times to complete 5 cumulative seconds of licking in the presence of the test stimuli on Day 21 are depicted in Figure 6. An ANOVA found an effect of test $\operatorname{CS}[F(1,44)=5.44, p<.05]$. Planned comparisons determined that Groups N-Tr-C and L-Ir-CN did not differ $(p>.25$ ), indicating that fear of the clicks was not attenuated by the white noise if the noise had not undergone inhibition training. However, Group N-Ir-CN yielded less suppression to the test CS(s) than did Groups L-Ir-CN and N-Tr-C $\left[F_{\mathrm{S}}(1,44) \geq 4.33\right.$, ps $\left.<.05\right]$, which indicates that training made the noise into an effective inhibitor. Notably, a comparison of Groups N-Tr-CN and $\mathrm{N}$-Ir-CN indicated that inflation treatment had no consequence on the inhibitory potential of the noise $(F<1.00)$.

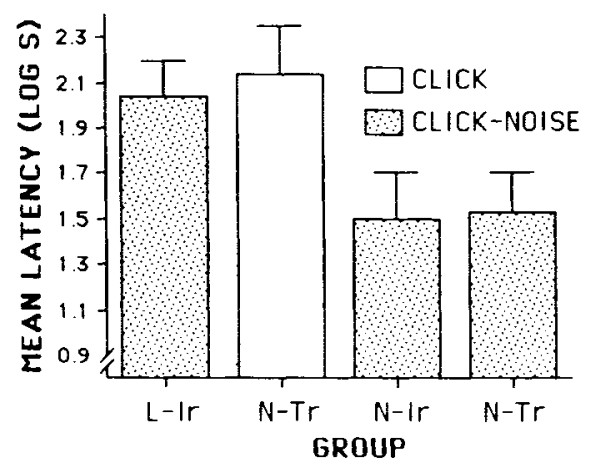

Figure 6. Mean times in Experiment 6 to complete 5 cumulative seconds of licking in the presence of the clicks or the click-noise compound. See text for group treatments. Brackets denote standard errors. 


\section{EXPERIMENT 7}

In Experiment 7, we sought to obtain backward blocking as an example of a posttraining inflation effect. Forward blocking (i.e., A-US, AX-US, test $\mathrm{X}$ ) can be viewed as a pretraining inflation of Stimulus $A$, which may serve as a comparator stimulus for Stimulus X. Kamin (1969) reported backward blocking (i.e., AX-US, A-US, test $X)$, but, without presenting supporting data, concluded that the apparent effect was due to forgetting of the X-US association during the A-US treatment period. Since we rarely see appreciable forgetting of aversive training, we decided to look for backward blocking with a control for forgetting. Our procedure was similar to that of Kamin.

\section{Method}

Subjects. The subjects were 24 rats of the same description as in Experiment 1. The subjects were assigned to two treatment groups $(n s=12)$

Apparatus. Context Irrelevant from Experiment 3 was the only apparatus used. A water-filled lick tube was present in the apparatus.

Procedure. See Table 1. On Days 1-4, all subjects were adapted to the context for $2 \mathrm{~h}$ per day. For target training on Days 5 and 6 , each subject spent $2 \mathrm{~h}$ daily in the apparatus, during which there were four randomly distributed, 3-min compound CS presentations, each reinforced at offset with a $0.5-\mathrm{sec}, 1.0-\mathrm{mA}$ shock. The compound CS consisted of a $25-\mathrm{W}$ flashing-light target stimulus $(0.5 \mathrm{sec}$ on $/ 0.5 \mathrm{sec}$ off) approximately $40 \mathrm{~cm}$ from the subject and a white noise $8 \mathrm{~dB}(\mathrm{C})$ above background. Inflation treatment occurred on Days 9-12 during 2-h daily sessions. In each session, the subjects in Group LN-N received four noise-shock pairings, with intensities and durations the same as in target training. The subjects in Group LN received comparable exposure to the context. On Day 13, all subjects were placed in the apparatus for $2 \mathrm{~h}$ in order to restore baseline licking. On Day 14, all subjects were returned to the apparatus for $16 \mathrm{~min}$. Upon completion of 5 cumulative seconds of licking, the light was presented until 5 additional seconds of licking were completed or a 15 -min ceiling was reached. On Day 15 , an identical test was conducted, with the noise serving as the test stimulus.

\section{Results and Discussion}

On Day 15, Group LN-N suppressed more to the white noise (mean $=1.99 \log \mathrm{sec}$ ) than did Group LN (mean $=1.62 \log \sec )[F(1,22)=4.33, p<.05]$. Thus, the inflation manipulation was effective in increasing fear of the noise. Mean times to complete the sacond 5 cumulative seconds of licking on Day 14 (i.e., in the presence of the light stimulus) were $1.50 \log \mathrm{sec}$ for Group LN and $1.62 \mathrm{log} s e c$ for Group LN-N $(p>.25)$. This lack of difference again demonstrates an absence of the inflation effect predicted by the comparator hypothesis.

\section{GENERAL DISCUSSION}

Over an extended series of experiments, posttraining inflation of a CS's comparator stimulus was found to have no effect on responding to the CS. This proved true regardless of whether the test looked at excitatory or inhibitory response potential. Collectively, these experiments constitute an inductive argument against the prediction of the comparator hypothesis that posttraining inflation of comparator stimuli will have an effect equal and opposite to that of posttraining extinction of comparator stimuli. Our results are concordant with Rescorla's (1989) observation that inflation of the training context during the later stages of CS training does little to reduce responding to the CS acquired prior to the occurrence of the unsignaled USs.

As with any null result, the conclusion must be qualified because the experiments may have been insensitive owing to inappropriate parameters or masking effects. However, other indicators of sensitivity suggest that the present studies would have been sensitive to any inflation effects that might have occurred. For example, the inflation manipulation was consistently seen to increase the associative strength of the putative comparator stimuli, and ceiling and floor effects were avoided on the CS tests. On the other hand, perhaps sensory preconditioning of the CS (mediated by the CS-comparator stimuli and comparator stimuli-US associations) allowed an increase in mediated responding to mask the effects of posttraining inflation of the comparator stimulus. However, it is not parsimonious to assume that the hypothetical gain in mediated responding (i.e., sensory preconditioning) was equal and opposite to the direct consequences of posttraining inflation, especially considering that this unlikely combination would have to obtain across all of the preparations used in these seven experiments. An additional qualification of the present results is required in light of reports that posttraining inflation of presumed comparator stimuli affects responding to the CS, as predicted by the comparator hypothesis under select circumstances. Specifically, inflation effects apparently can be obtained if the comparator stimuli were inflated before or during CS training, deflated after CS training, and then reinflated prior to test (Best, Dunn, Batson, Meachum, \& Nash, 1985; Lysle \& Fowler, 1985).

In summary, we conclude that there is likely a fundamental asymmetry between the effects of posttraining extinction (deflation) and postraining inflation of comparator stimuli on responding to the CS. The failure of inflation is grounds to seriously question the response rule that we have termed the comparator hypothesis, which states: Responding to a CS varies directly with the associative strength of the CS and inversely with the associative strength of cues that were present during CS training, where the relevant associations are those in force at the time of the test trial (e.g., Miller \& Matzel, 1988).

Despite the failure of the prediction concerning posttraining inflation, we should be slow to discard the comparator hypothesis, since it is unique in making a number of confirmed predictions concerning posttraining extinction of comparator stimuli (see the introduction of this paper). These successes pose serious problems for most of the prevailing theories of associative acquisition (e.g., Rescorla \& Wagner, 1972). However, the predicted effects of posttraining extinction of comparator stimuli are not always observed. For example, deflation after truly random exposure (i.e., learned irrelevance treatment) appears to be ineffective (Miller, 1987; Robbins, 1988). 
However, the extinction manipulation is effective in the great majority of cases that we have examined. Without the comparator hypothesis, these effects of posttraining extinction of comparator stimuli might not have been discovered. Thus, the comparator hypothesis has been of considerable heuristic value despite its being partially incorrect.

\section{REFERENCES}

Best, M. R., Dunn, D. P., Batson, J. D., Meachum, C. L., \& NASH, S. M. (1985). Extinguishing conditioned inhibition in flavoraversion learning: Effects of repeated testing and extinction of the excitatory element. Quarterly Journal of Experimental Psychology, 37B, 359-378.

Hallam, S. C., Matzel, L. D., Sloat, J., \& Miller, R. R. (1990). Excitation and inhibition as a function of posttraining extinction of the excitatory cue used in Pavlovian inhibitory training. Learning \& Motivation, 21, 59-84.

HALlam, S. C., Miller, R. R. (1988). [Exploring contingency space]. Unpublished raw data.

KAMIN, L. J. (1969). Selective association and conditioning. In N. J. Mackintosh \& W. K. Honig (Eds.), Fundamental issues in associative leaming (pp. 42-64). Halifax, NS: Dalhousie University Press.

KaPLAN, P. S., \& Hearst, E. (1985). Excitation, inhibition, and context: Studies of extinction and reinstatement. In P. D. Balsam \& A. Tomie (Eds.), Context and learning (pp. 195-224). Hillsdale, NJ: Erlbaum.

Kasprow, W. J., Schachtman, T. R., Miller, R. R. (1987). The comparator hypothesis of conditioned response generation: Manifest conditioned excitation and inhibition as a function of relative excitatory associative strengths of $\mathrm{CS}$ and conditioning context at the time of testing. Journal of Experimental Psychology: Animal Behavior Processes, 13, 395-406.

LYSLE, D. T., \& Fowler, F. (1985). Inhibition as a "slave" process: Deactivation of conditioned inhibition through extinction of conditioned excitation. Journal of Experimental Psychology: Animal Behavior Processes, 11, 71-94.

Matzel, L. D., Brown, A. M., \& Miller, R. R. (1987). Associative effects of US preexposure: Modulation of conditioned responding by an excitatory training context. Journal of Experimental Psychology: Animal Behavior Processes, 13, 65-72.

Matzel, L. D., Schachtman, T. R., \& MilleR, R. R. (1985). Recovery of an overshadowed association achieved by extinction of the overshadowing stimulus. Learning \& Motivation, 16, 398-412.

Miller, R. R. (1987). [Learned irrelevance and comparator stimuli]. Unpublished raw data.

MilleR, R. R., \& MATZEL, L. D. (1988). The comparator hypothesis: A response rule for the expression of associations. In $\mathrm{G}$. H. Bower (Ed.), The psychology of learning and motivation (Vol. 22, pp. 5192). San Diego, CA: Academic Press.

Miller, R. R., \& Schachtman, T. R. (1985). Conditioning context as an associative baseline: Implications for response generation and the nature of conditioned inhibition. In R. R. Miller \& N. E. Spear (Eds.), Information processing in animals: Conditioned inhibition (pp. 51-88). Hillsdale, NJ: Erlbaum.

ReIsS, S., \& W AGNER, A. R. (1972). CS habituation produces a "latent inhibition effect" but no active "conditioned inhibition." Learning \& Motivation, 3, 237-245.

RESCORLA, R. A. (1971). Summation and retardation tests of latent inhibition. Journal of Comparative \& Physiological Psychology, 75, 77-81.

Rescorla, R. A. (1989). Redundant treatments of neutral and excitatory stimuli in autoshaping. Journal of Experimental Psychology: Animal Behavior Processes, 15, 212-223.

Rescorla, R. A., W Wagner, A. R. (1972). A theory of Pavlovian conditioning: Variations in the effectiveness of reinforcement and nonreinforcement. In A. H. Black \& W. F. Prokasy (Eds.), Classical conditioning II: Current research and theory (pp. 64-99). New York: Appleton-Century-Crofts.

RobiINs, S. J. (1988). The role of context in performance on a random schedule in autoshaping. Joumal of Experimental Psychology: Animal Behavior Processes, 14, 413-424.

Schachtman, T. R., Brown, A. M., Gordon, E., Catterson, D., * Miller, R. R. (1987). Mechanisms underlying retarded emergence of conditioned responding following inhibitory training: Evidence for the comparator hypothesis. Journal of Experimental Psychology: Animal Behavior Processes, 13, 310-322.

(Manuscript received September 27, 1989; revision accepted for publication June 1,1990 .) 